\title{
Mycoplasma hominis and Mycoplasma genitalium in the Vaginal Microbiota and Persistent High-Risk Human Papillomavirus Infection
}

\begin{abstract}
Sally N. Adebamowo ${ }^{1,2 *}$, Bing Ma ${ }^{3,4}$, Davide Zella ${ }^{5}$, Ayotunde Famooto ${ }^{6}$, Jacques Ravel/,4, Clement Adebamowo ${ }^{1,2,5,6}$ and ACCME Research Group ${ }^{6}$

${ }^{1}$ Department of Epidemiology and Public Health, University of Maryland School of Medicine, Baltimore, MD, United States, ${ }^{2}$ University of Maryland Comprehensive Cancer Center, University of Maryland School of Medicine, Baltimore, MD, United States, ${ }^{3}$ Institute for Genome Sciences, University of Maryland, Baltimore, MD, United States, ${ }^{4}$ Department of Microbiology and Immunology, University of Maryland School of Medicine, Baltimore, MD, United States, ${ }^{5}$ Institute of Human Virology, University of Maryland School of Medicine, Baltimore, MD, United States, ${ }^{6}$ Institute of Research Virology Nigeria, Abuja, Nigeria
\end{abstract}

Background: Recent studies have suggested that the vaginal microenvironment plays a role in persistence of high-risk human papillomavirus (hrHPV) infection and thus cervical carcinogenesis. Furthermore, it has been shown that some mycoplasmas are efficient methylators and may facilitate carcinogenesis through methylation of hrHPV and cervical somatic cells. We examined associations between prevalence and persistence of Mycoplasma spp. in the vaginal microbiota, and prevalent as well as persistent hrHPV infections.

Methods: We examined 194 Nigerian women who were tested for hrHPV infection using $\mathrm{SPF}_{25} / \mathrm{LiPA}_{10}$ and we identified Mycoplasma genitalium and Mycoplasma hominis in their vaginal microbiota established by sequencing the $\mathrm{V} 3-\mathrm{V} 4$ hypervariable regions of the $16 \mathrm{~S}$ rRNA gene. We defined the prevalence of $M$. genitalium, M. hominis, and hrHPV based on positive result of baseline tests, while persistence was defined as positive results from two consecutive tests. We used exact logistic regression models to estimate associations between Mycoplasma spp. and hrHPV infections.

Results: The mean (SD) age of the study participants was 38 (8) years, $71 \%$ were HIV positive, 30\% M. genitalium positive, 45\% M. hominis positive, and 40\% hrHPV positive at baseline. At follow-up, 16\% of the women remained positive for $M$. genitalium, 30\% for M. hominis, and 31\% for hrHPV. There was a significant association between persistent M. hominis and persistent hrHPV (OR 8.78, 95\% Cl 1.49-51.6, p 0.01). Women who were positive for HIV and had persistent $M$. hominis had threefold increase in the odds of having persistent hrHPV infection (OR 3.28, 95\% Cl 1.31-8.74, p 0.008), compared to women who were negative for both.

Conclusion: We found significant association between persistent $M$. hominis in the vaginal microbiota and persistent hrHPV in this study, but we could not rule out reverse causation. Our findings need to be replicated in larger, longitudinal studies and if confirmed, could have important diagnostic and therapeutic implications.

Keywords: Mycoplasma hominis, Mycoplasma genitalium, vaginal microbiota, persistent high-risk HPV, human papillomavirus, Nigeria 


\section{INTRODUCTION}

Globally, cervical cancer is the fourth most common cancer in women, with an estimated 528,000 new cancers in 2012 (1). It is one of the two commonest cancers in low- and middle-income countries where the mortality rate from cervical cancer is also very high. Persistent high-risk human papillomavirus (hrHPV) infection is a necessary but not sufficient cause for cervical intraepithelial neoplasm grades $2 / 3$ and cervical cancer (2). While most hrHPV infections are cleared within 2 years, it persists in about $12 \%$ of women who remain at an elevated risk for the development of cervical cancer (3). Although the reasons for this variable natural history continue to be studied, it is generally accepted that several cofactors are important for the development of cervical cancer in hrHPV-infected women $(2,4)$. Identification of these cofactors will improve understanding of cervical carcinogenesis and identify new opportunities for prevention and treatment of cervical cancer.

Sexually transmitted genital pathogens such as HIV, herpes simplex virus, Neisseria gonorrhea, Chlamydia trachomatis, Gardnerella vaginalis, Trichomonas vaginalis, Ureaplasma urealyticum, Ureaplasma parvum, and Treponema pallidum have been identified as possible cofactors of persistent hrHPV infection in cervical carcinogenesis. However, the results from previous studies have been inconsistent (5-11). Several pathogens, particularly those capable of establishing persistent infections can affect cellular apoptotic pathways and potentially facilitate abnormal cell growth (12). Some Mycoplasma spp. have been shown to be capable of persistent infections and induction of somatic cellular chromosomal alterations that lead to neoplastic transformation in several tissues (13-19). Few studies have examined the relationship between some Mycoplasma spp. and risk of hrHPV infections or CIN2+ in women $(6,8-10)$. Some of these studies showed no associations between Mycoplasma genitalium and hrHPV infections $(8,10)$, non-significant associations between M. genitalium, Mycoplasma hominis, and hrHPV infections (9), or significant associations between $M$. genitalium, M. hominis, and hrHPV infections (6). To date, no study has examined the association between prevalence or persistence of Mycoplasma spp. and persistent hrHPV infections.

In this study, we examined associations between prevalent and persistent M. genitalium and M. hominis, and hrHPV infections in a cohort of Nigerian women.

\section{MATERIALS AND METHODS}

\section{Study Population}

We studied 1,020 women who were enrolled in a study of HPV infection and cervical cancer at National Hospital, Abuja and University of Abuja Teaching Hospital, Nigeria, between 2012 and 2014. All the study participants were 18 years or older, had a history of vaginal sexual intercourse, were not currently pregnant and had no history of hysterectomy. Trained nurses collected data on socio-demographic characteristics, sexual and reproductive history, and self-reported HIV status of the participants. We confirmed self-reported HIV status of participants from the hospitals' medical records. The nurses collected venous blood samples and performed pelvic examinations on all study participants at each study visit. We used Elution swab systems (Copan, Italy) to collect mid-vaginal swabs and cervical brushes to collect exfoliated cervical cells, which were inserted in $1 \mathrm{ml}$ Amies' transport media (Copan). Participants were asked to return for follow-up after 6 months, at which time, the history, physical examinations, and samples' collections were repeated. All samples were stored at $-80^{\circ} \mathrm{C}$, until processing for further analysis. In this analysis, we included 194 women who had data on mycoplasma and HPV.

\section{HPV Detection by $\mathrm{SPF}_{10} / \mathrm{LiPA}_{25}$}

We extracted DNA from cervical exfoliated cells as previously described (5). Samples were tested for the presence of HPV DNA by hybridization of $\mathrm{SPF}_{10}$ amplimers to a mixture of general HPV probes recognizing a broad range of HPV genotypes in a microtiter plate format, as previously described (20). All samples determined to be HPV DNA positive by $\mathrm{SPF}_{10}$ DNA Enzyme Immunoassay (DEIA) were genotyped using the $\mathrm{LiPA}_{25}$ version 1. The $\mathrm{LiPA}_{25}$ assay provides type-specific information for 25 different HPV genotypes simultaneously and identifies infection by one or more of 13 hrHPV genotypes: 16, 18, 31, 33, 35, 39, 45, $51,52,56,58,59$, and $68(21,22)$. We defined hrHPV infection as prevalent if at least one hrHPV genotype was detected by the $\mathrm{SPF}_{10} / \mathrm{LiPA}_{25}$ test in a sample provided at the baseline visit; and persistent if at least one hrHPV genotype was detected by the $\mathrm{SPF}_{10} / \mathrm{LiPA}_{25}$ test in samples provided at the baseline and followup visits.

\section{Sequencing and Analysis of Barcoded 16S rRNA Gene Amplicons}

We extracted genomic DNA from mid-vaginal swabs as previously described (23). Dual barcode system fusion primers 338 and

TABLE 1 | Baseline characteristics of women in the study population.

\begin{tabular}{|c|c|c|c|}
\hline & $\begin{array}{c}\text { All } \\
\text { participants, } \\
n=194\end{array}$ & $\begin{array}{c}\text { HIV } \\
\text { positive, } \\
n=139\end{array}$ & $\begin{array}{c}\text { HIV } \\
\text { negative, } \\
n=55\end{array}$ \\
\hline & \multicolumn{3}{|c|}{ Mean (SD) } \\
\hline \multicolumn{4}{|l|}{ Characteristics } \\
\hline Age, years & $38(8)$ & $38(8)$ & $38(9)$ \\
\hline Body mass index, $\mathrm{kg} / \mathrm{m}^{2}$ & $27(5)$ & $26(4)$ & $29(6)$ \\
\hline Age at sexual initiation, years & $19(3)$ & $19(3)$ & $20(4)$ \\
\hline \multirow[t]{2}{*}{ Total sex partners } & $4(3)$ & $4(3)$ & $3(2)$ \\
\hline & \multicolumn{3}{|c|}{ n (\%) } \\
\hline \multicolumn{4}{|l|}{ Marital status } \\
\hline Married & $111(57)$ & $72(52)$ & $39(71)$ \\
\hline Not married & $83(43)$ & $67(48)$ & $16(29)$ \\
\hline \multicolumn{4}{|l|}{ Education, years completed } \\
\hline$\leq 6$ years & $23(12)$ & $17(12)$ & $6(11)$ \\
\hline $7-12$ & $125(64)$ & $100(72)$ & $25(45)$ \\
\hline$>12$ & $46(24)$ & $22(16)$ & $24(44)$ \\
\hline Contraceptive use & $75(37)$ & $46(33)$ & $29(53)$ \\
\hline Condom use & $1(0.5)$ & $1(0.7)$ & $0(0)$ \\
\hline Douching & $129(66)$ & $96(69)$ & $33(60)$ \\
\hline \multicolumn{4}{|l|}{ Menopausal status } \\
\hline Pre-menopausal & $161(83)$ & $117(85)$ & $44(80)$ \\
\hline Post-menopausal & $32(17)$ & $21(15)$ & $11(20)$ \\
\hline
\end{tabular}


806R were used for PCR amplification of the V3-V4 hypervariable regions of the $16 \mathrm{~S}$ rRNA gene as previously described (24). Both positive and negative controls for DNA extraction and PCR amplification were included. Amplicons were pooled and sequenced on an Illumina MiSeq instrument using the 300 bp paired-end protocol, at the Institute for Genome Sciences, University of Maryland School of Medicine. Raw reads were preprocessed to remove the first 3 and last 3 bases if their Phred score was lower than 3. Read ends were trimmed if the average Phred quality score of 4 consecutive bases was below 15. Paired reads were retained if their length was at least $75 \%$ of their original length after trimming. QIIME (v1.8.0) (25) was used to perform quality control of the sequence reads. Reads were assembled using Fast Length Adjustment of Short reads (FLASH) (26), with an overlap of $\sim 90$ bp on average. Assembled reads were de-multiplexed by binning sequences with the same dual barcode. Both de novo and reference-based chimera detection were conducted in UCHIME (v5.1) using Greengenes database of 16S rRNA gene sequences (Aug 2013) as a reference $(27,28)$. The processed $16 \mathrm{~S}$ rRNA gene amplicon sequences were assigned to genera and species, using PECAN that uses fifth-order Markov Chain model for precise species-level assignments and a pre-compiled database that contains all known microbes in the vaginal microbiota. Ward linkage clustering was used to cluster samples based on their Jensen-Shannon distance calculated in vegan package in R (29). M. genitalium and M. hominis were defined as prevalent if at least one read of the spp. was detected by sequencing, in a sample provided at the baseline visit and persistent if at least one read of the spp. was detected by sequencing, in samples provided at the baseline and follow-up visits.

\section{Statistical Analysis}

We managed participants' data using REDCap electronic database, hosted at the Institute of Human Virology Nigeria (30, 31). While all of these women had complete data on M. hominis and HPV at both visits, 27\% (52/194) did not have data on $M$. genitalium at baseline and were excluded from the M. genitalium analysis. We examined differences in the distribution of continuous variables between groups using $t$-tests and used $\chi^{2}$ and Fisher's exact tests for categorical variables. We used exact logistic regression $(32,33)$ to examine the associations between M. genitalium and hrHPV infections, and M. hominis and hrHPV infections. We considered characteristics that were significant at the $p<0.20$ level in age adjusted analyses for inclusion in multivariate models. All analyses were performed using SAS 9.3 for UNIX statistical software (SAS Institute, Gary, NC, USA).

\section{Ethics}

The study was conducted according to the Nigerian National Code for Health Research Ethics. Ethical approval to conduct this study was obtained from the Institute of Human Virology
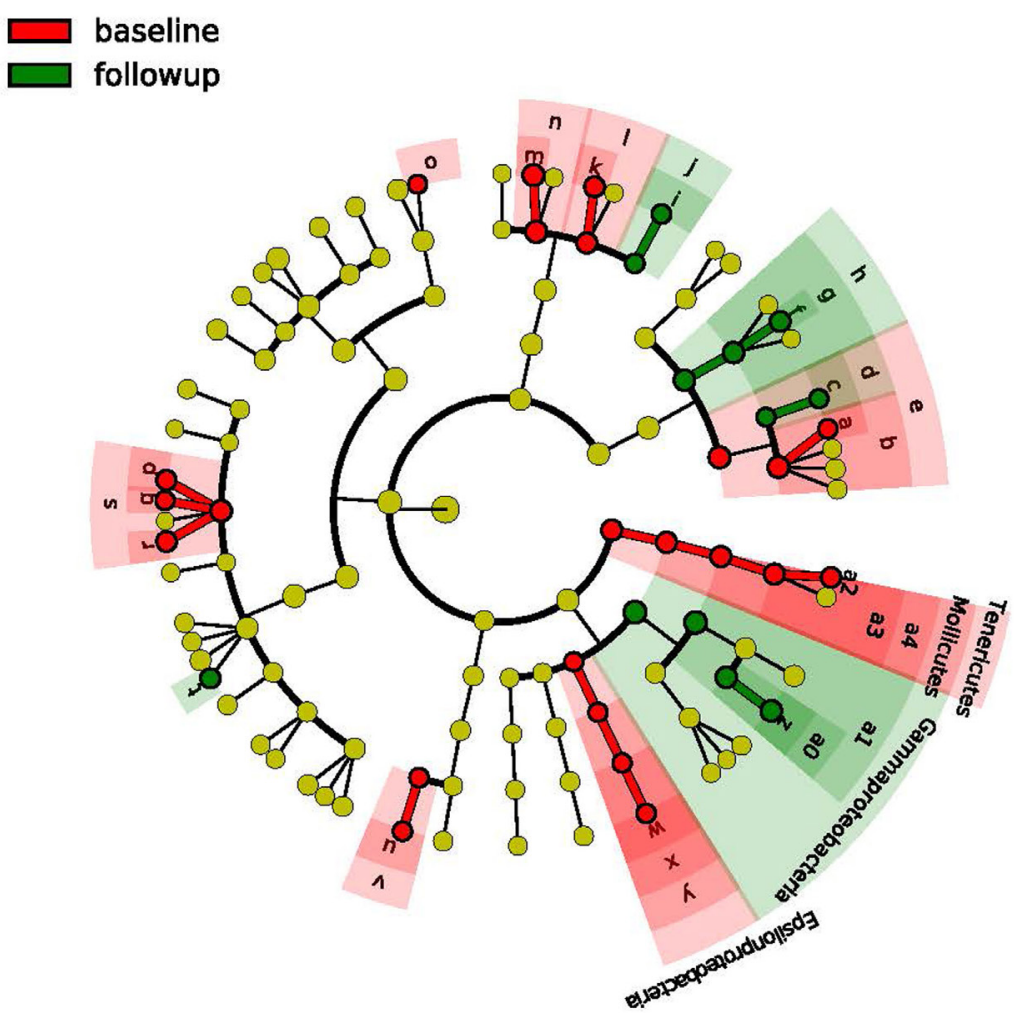

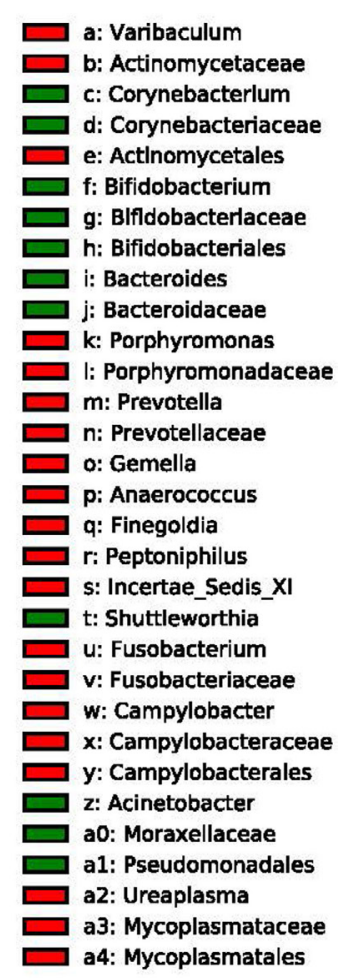

FIGURE 1 | Cladogram representing the taxonomic hierarchical structure of the identified phylotype biomarkers. Each filled circles represents one biomarker; red, phylotypes statistically overrepresented at baseline; green, phylotypes overrepresented at follow-up. The diameter of a circle is proportional to the phylotype's relative abundance; phylum and class are marked in their names on the Cladogram; and the order, family, or genera are named in alphabets and labeled in legend. 


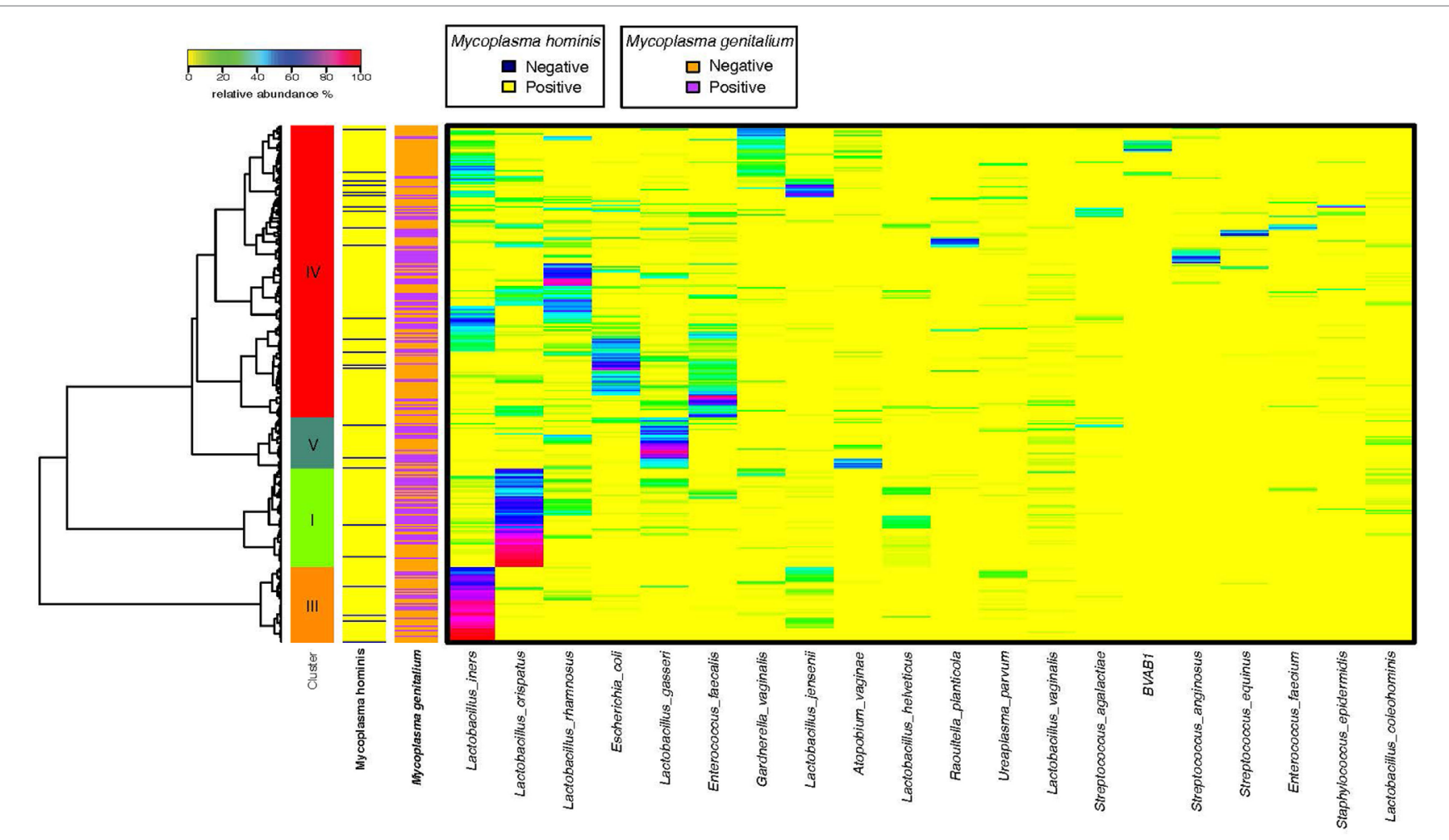

FIGURE 2 | Community survey of vaginal microbiota samples collected from 194 female participants enrolled in this study. Relative abundance of the 20 most abundant phylotypes are shown in heatmap. Ward linkage clustering is used to clusters samples based on their Jensen-Shannon distance calculated in vegan package in R (29). Identified community state types (CSTs) are labeled as I, III, and IV, according to the previous naming convention (34).

TABLE 2 | Distribution of mycoplasma and high-risk human papillomavirus (hrHPV) in the study population in total and by HIV status.

\begin{tabular}{ccccc}
\hline & All participants & HIV positive & HIV negative & p-Value \\
\hline M. genitalium & $n=142$ & $n=101$ & $n=41$ & \\
Prevalence & $43(30.3)$ & $28(27.7)$ & $15(36.6)$ & 0.31 \\
Persistence & $23(16.2)$ & $23(22.7)$ & $0(0)$ & $<0.001$ \\
M. hominis & $n=194$ & $n=139$ & $n=55$ & \\
Prevalence & $87(44.8)$ & $48(34.5)$ & $39(70.1)$ & $<0.001$ \\
Persistence & $59(30.4)$ & $58(41.7)$ & $1(1.7)$ & $<0.001$ \\
hrHPV & $n=194$ & $n=139$ & $n=55$ & \\
Prevalence & $77(39.7)$ & $63(45.3)$ & $14(25.4)$ & 0.01 \\
Persistence & $60(30.9)$ & $50(35.9)$ & $10(18.2)$ & 0.01 \\
\hline
\end{tabular}

Nigeria health research ethics committee and the University of Maryland School of Medicine Institutional Review Board. Written informed consent was obtained from all participants before enrollment in the study.

\section{RESULTS}

The mean (SD) age of the participants was 38 (8) years while their mean $(\mathrm{SD})$ body mass index (BMI $\left[\mathrm{kg} / \mathrm{m}^{2}\right]$ ) was $27(5)$. Most $(57 \%$, $111 / 194)$ of the participants were married and premenopausal (83\%, 161/194). The characteristics of the study participants at baseline are shown in Table 1. Participants returned for follow-up visits at a median (IQR) time of 5.7 (5.4-7.5) months.
TABLE 3 | High-risk human papillomavirus (hrHPV) types among the 194 study participants, in decreasing order of prevalence.

\begin{tabular}{lcc}
\hline HPV types & Prevalent hrHPV $\boldsymbol{n}(\%)$ & Persistent hrHPV $\boldsymbol{n}(\%)$ \\
\hline HPV 52 & $23(11.9)$ & $20(10.3)$ \\
HPV 35 & $22(11.3)$ & $17(8.8)$ \\
HPV 18 & $9(4.6)$ & $4(2.1)$ \\
HPV 31 & $9(4.6)$ & $8(4.1)$ \\
HPV 33 & $8(4.1)$ & $3(1.6)$ \\
HPV 51 & $7(3.6)$ & $5(2.6)$ \\
HPV 16 & $6(3.1)$ & $4(2.1)$ \\
HPV 56 & $5(2.6)$ & $2(1.0)$ \\
HPV 59 & $5(2.6)$ & $1(0.5)$ \\
HPV 58 & $4(2.1)$ & $3(1.6)$ \\
HPV 45 & $4(2.1)$ & $3(1.6)$ \\
HPV 39 & $3(1.6)$ & $2(1.0)$ \\
\hline
\end{tabular}

We obtained mid-vaginal samples at baseline and at follow-up visits from 194 participants yielding 388 samples from which we generated a total of 12.9 million high quality reads with about 36,609 reads per sample. We identified 122 unique operational taxonomic units (OTUs) in this study population. Figure 1 shows the taxonomic hierarchical structure of the identified phylotype biomarkers. We observed four community state types (CSTs) of vaginal microbiota based on community composition and structure. Three of these CSTs were dominated by Lactobacillus crispatus, L. iners, and L. gasseri, while the fourth comprised a 
TABLE 4 | Association between potential risk factors and high-risk human papillomavirus (hrHPV) infections.

\begin{tabular}{|c|c|c|c|c|c|c|c|}
\hline \multirow[t]{2}{*}{ Variable } & \multirow[t]{2}{*}{ Total $n$} & \multicolumn{3}{|c|}{ Prevalent hrHPV } & \multicolumn{3}{|c|}{ Persistent hrHPV } \\
\hline & & $n(\%)$ & OR $(95 \% \mathrm{Cl})$ & $p$-Value & $n(\%)$ & OR $(95 \% \mathrm{Cl})$ & $p$-Value \\
\hline \multicolumn{8}{|l|}{ Age, years } \\
\hline$<30$ & 19 & $6(31)$ & $0.59(0.14-2.17)$ & 0.55 & $4(21)$ & $0.64(0.12-2.77)$ & 0.74 \\
\hline 30 to $<45$ & 141 & $55(39)$ & $0.81(0.33-1.87)$ & 0.72 & $46(32)$ & $1.16(0.48-2.95)$ & 0.88 \\
\hline$\geq 45$ & 34 & $15(44)$ & Ref. (1.00) & & $10(29)$ & Ref. (1.00) & \\
\hline \multicolumn{8}{|l|}{ Body mass index, $\mathrm{kg} / \mathrm{m}^{2}$} \\
\hline Normal weight, 18.5 to $<25$ & 62 & $31(50)$ & $1.98(0.85-4.71)$ & 0.11 & 24 (39) & $2.38(0.94-6.38)$ & 0.06 \\
\hline Overweight, 25 to $<30$ & 75 & $24(32)$ & $0.94(0.40-2.20)$ & 1.00 & $22(29)$ & $1.57(0.62-4.17)$ & 0.40 \\
\hline Obese, $\geq 30$ & 48 & $16(33)$ & Ref. (1.00) & & $10(21)$ & Ref. (1.00) & \\
\hline \multicolumn{8}{|l|}{ Marital status } \\
\hline Married & 111 & $44(40)$ & $1.04(0.56-1.95)$ & 0.99 & $35(31)$ & $1.06(0.55-2.08)$ & 0.95 \\
\hline Not married & 83 & $32(38)$ & Ref. (1.00) & & $25(30)$ & Ref. (1.00) & \\
\hline \multicolumn{8}{|l|}{ Education, years completed } \\
\hline$\leq 6$ years & 23 & $14(61)$ & $2.61(0.84-8.49)$ & 0.10 & $9(39)$ & $1.46(0.44-4.69)$ & 0.64 \\
\hline $7-12$ & 125 & $45(36)$ & $0.96(0.45-2.07)$ & 1.00 & $37(20)$ & $0.96(0.43-2.18)$ & 1.00 \\
\hline$>12$ & 46 & $17(37)$ & Ref. (1.00) & & $14(30)$ & Ref. (1.00) & \\
\hline \multicolumn{8}{|c|}{ Age at sexual initiation, years } \\
\hline$\leq 19$ & 98 & $41(42)$ & $1.61(0.59-4.17)$ & 0.42 & $33(34)$ & $1.14(0.41-3.36)$ & 0.97 \\
\hline $19-22$ & 67 & $26(39)$ & $1.42(0.49-4.35)$ & 0.63 & $19(28)$ & $0.89(0.30-2.78)$ & 1.00 \\
\hline$>22$ & 26 & $8(31)$ & Ref. (1.00) & & $8(31)$ & Ref. (1.00) & \\
\hline \multicolumn{8}{|l|}{ Total lifetime sex partners } \\
\hline 1 & 31 & $8(26)$ & $0.62(0.20-1.80)$ & 0.48 & $7(23)$ & $0.61(0.18-1.85)$ & 0.49 \\
\hline $2-4$ & 106 & $48(45)$ & $1.48(0.72-3.08)$ & 0.31 & $35(33)$ & $1.04(0.49-2.22)$ & 1.00 \\
\hline$\geq 5$ & 56 & $20(36)$ & Ref. (1.00) & & $18(32)$ & Ref. (1.00) & \\
\hline \multicolumn{8}{|l|}{ Vaginal pH } \\
\hline$<4.5$ & 9 & $1(11)$ & $0.20(0.04-1.56)$ & 0.18 & $0(0)$ & - & \\
\hline 4.5 to $<5.5$ & 13 & $9(69)$ & $3.58(0.95-16.6)$ & 0.06 & $9(69)$ & $5.28(1.39-24.5)$ & 0.01 \\
\hline$\geq 5.5$ & 172 & $66(38)$ & Ref. (1.00) & & $51(30)$ & Ref. (1.00) & \\
\hline \multicolumn{8}{|l|}{ HIV status } \\
\hline Positive & 139 & $62(45)$ & $2.34(1.13-5.10)$ & 0.01 & $50(36)$ & $2.51(1.12-6.09)$ & 0.02 \\
\hline Negative & 55 & $14(25)$ & Ref. (1.00) & & $10(18)$ & Ref. (1.00) & \\
\hline
\end{tabular}

Table shows exact odds ratios (ORs) and 95\% confidence intervals (Cls) based on logistic regression models.

$n$, number of women.

diverse set of strict and facultative anaerobes. Figure 2 shows the top 20 most abundant bacterial taxa, and M. genitalium and M. hominis in the vaginal microbiota.

At baseline, 72\% (139/194) of the women were positive for HIV, $30 \%$ (43/142) for M. genitalium, 45\% (87/194) for M. hominis, and $40 \%$ (77/194) for hrHPV. Fewer women $(16 \%, 23 / 142)$ were persistently positive for M. genitalium, 30\% (59/194) for M. hominis, and 31\% (60/194) for hrHPV. The distribution of Mycoplasma spp. and hrHPV in the study population in total and by HIV status is shown in Table 2. HIV positive women were significantly positive for persistent $M$. genitalium ( $p<0.001)$, M. hominis $(p<0.001)$, and hrHPV $(p<0.01)$ compared to HIV negative women. HPV52 $(10 \%, 20 / 194)$ and HPV35 $(9 \%, 17 / 194)$ were the most common persistent hrHPV infections in the study population (Table 3 ). HIV infection was positively associated with prevalent hrHPV (OR 2.34, 95\% CI 1.13-5.10, p 0.01) and persistent high-risk HPV infections (OR 2.51, 95\% CI 1.12-6.09, p 0.02), Table 4.

We examined several variables for associations with M. genitalium and M. hominis (Tables 5 and 6). HIV infection was significantly associated with prevalent and persistent M. hominis. Given that HIV was also associated with hrHPV infections, we adjusted for this variable in multivariate models examining the associations between M. genitalium and
M. hominis, and hrHPV infections. In the age adjusted analyses, the association between persistent $M$. hominis and persistent hrHPV was statistically significant (OR 11.1, 95\% CI 2.37-51.6, p 0.002). This association remained statistically significant, after further adjustment for HIV status (OR 8.78, 95\% CI 1.49-51.6, p-value 0.01) Table 7. Among the women, we also observed that there was significant association between HIV and prevalent M. hominis positivity, and prevalent hrHPV (OR 5.53, 95\% CI $1.08-55.2, p$ 0.03), compared to HIV and prevalent $M$. hominis negative women. Similarly, there was significant association between HIV and persistent M. hominis positivity, and persistent hrHPV infections (OR 3.28, 95\% CI 1.31-8.74, p 0.008), compared to HIV and persistent $M$. hominis negative women. There was no significant association between being positive for HIV and prevalent or persistent M. genitalium, and prevalent or persistent hrHPV infection.

\section{DISCUSSION}

This is the first study to examine associations between persistent M. genitalium and M. hominis in the vaginal microbiota and prevalent as well as persistent hrHPV infections to our knowledge. We found high prevalence and persistence of $M$. hominis 
TABLE 5 | Association between sociodemographic characteristics and potential risk factors for Mycoplasma genitalium.

\begin{tabular}{|c|c|c|c|c|c|c|c|}
\hline \multirow[t]{2}{*}{ Variable } & \multirow[t]{2}{*}{ Total $n(n=142)$} & \multicolumn{3}{|c|}{ Prevalent $M$. genitalium } & \multicolumn{3}{|c|}{ Persistent $M$. genitalium } \\
\hline & & $n(\%)$ & OR $(95 \% \mathrm{Cl})$ & $p$-Value & & OR $(95 \% \mathrm{Cl})$ & $p$-Value \\
\hline \multicolumn{8}{|l|}{ Age, years } \\
\hline$<30$ & 13 & $3(23)$ & $0.77(0.10-4.44)$ & 1.00 & $3(23)$ & $0.76(0.19-24.7)$ & 0.75 \\
\hline 30 to $<45$ & 104 & $33(32)$ & $1.19(0.42-3.72)$ & 0.91 & $17(16)$ & $1.68(0.35-10.9)$ & 0.71 \\
\hline$\geq 45$ & 25 & $7(28)$ & Ref. (1.00) & & $3(12)$ & Ref. (1.00) & \\
\hline \multicolumn{8}{|l|}{ Body mass index, $\mathrm{kg} / \mathrm{m}^{2}$} \\
\hline Normal weight, 18.5 to $<25$ & 45 & $17(38)$ & $1.60(0.55-4.90)$ & 0.46 & $6(13)$ & $1.84(0.34-11.1)$ & 0.63 \\
\hline Overweight, 25 to $<30$ & 61 & $16(26)$ & $0.94(0.33-2.82)$ & 1.00 & $12(20)$ & $2.93(0.68-15.4)$ & 0.18 \\
\hline Obese, $\geq 30$ & 33 & $9(27)$ & Ref. (1.00) & & $4(12)$ & Ref. (1.00) & \\
\hline \multicolumn{8}{|l|}{ Marital status } \\
\hline Married & 84 & $21(25)$ & $0.58(0.24-1.20)$ & 0.14 & $16(19)$ & $1.48(0.44-5.21)$ & 0.64 \\
\hline Not married & 58 & $22(38)$ & Ref. (1.00) & & $7(12)$ & Ref. (1.00) & \\
\hline \multicolumn{8}{|l|}{ Education, years completed } \\
\hline$\leq 6$ years & 14 & $4(28)$ & $0.68(0.12-3.01)$ & 0.82 & $0(0)$ & - & \\
\hline $7-12$ & 93 & $26(28)$ & $0.65(0.26-1.64)$ & 0.42 & $19(20)$ & $2.91(0.75-14.1)$ & 0.14 \\
\hline$>12$ & 35 & $13(37)$ & Ref. (1.00) & & $4(11)$ & Ref. (1.00) & \\
\hline \multicolumn{8}{|c|}{ Ageat sexual initiation, years } \\
\hline$\leq 19$ & 75 & $24(32)$ & $1.01(0.31-3.68)$ & 1.00 & $14(19)$ & $8.23(0.93-72.4)$ & 0.06 \\
\hline $19-22$ & 47 & $13(28)$ & $0.83(0.23-3.25)$ & 0.97 & $8(17)$ & $5.00(0.54-46.2)$ & 0.15 \\
\hline$>22$ & 19 & $6(31)$ & Ref. (1.00) & & $1(5)$ & Ref. (1.00) & \\
\hline \multicolumn{8}{|l|}{ Total lifetime sex partners } \\
\hline 1 & 21 & $5(24)$ & $0.49(0.12-1.73)$ & 0.35 & $3(14)$ & $0.55(0.07-3.18)$ & 0.71 \\
\hline $2-4$ & 72 & $19(36)$ & $0.59(0.24-1.32)$ & 0.21 & $13(18)$ & $1.43(0.39-5.47)$ & 0.74 \\
\hline$\geq 5$ & 49 & $19(39)$ & Ref. (1.00) & & $7(14)$ & Ref. (1.00) & \\
\hline \multicolumn{8}{|l|}{ Vaginal pH } \\
\hline$<4.5$ & 3 & $0(0)$ & - & - & $2(67)$ & $3.90(0.33-45.6)$ & 0.27 \\
\hline 4.5 to $<5.5$ & 9 & $1(11)$ & $0.24(0.01-2.07)$ & 0.34 & $1(11)$ & $0.65(0.06-6.65)$ & 0.71 \\
\hline$\geq 5.5$ & 130 & $42(32)$ & Ref. (1.00) & & $20(15)$ & Ref. (1.00) & \\
\hline \multicolumn{8}{|l|}{ HIV status } \\
\hline Yes & 101 & $28(28)$ & $0.66(0.28-1.56)$ & 0.39 & $23(23)$ & - & \\
\hline No & 41 & $15(36)$ & Ref. (1.00) & & $0(0)$ & Ref. (1.00) & \\
\hline
\end{tabular}

Table shows exact odds ratios (ORs) and 95\% confidence intervals (Cls) based on logistic regression models; $n=$ number of women.

and M. genitalium in the vaginal microbiota of our study participants. There was significant association between persistent M. hominis and persistent hrHPV infections independent of HIV status.

Previous studies of the prevalence of cervico-vaginal Mycoplasma spp. in African women include studies of commercial sex workers in Kenya where the prevalence of M. genitalium was $13 \%$ and in Niger Republic where the prevalence of M. hominis was $37 \%(35,36)$. Another study of M. hominis among HIV-positive women found a prevalence of $16.7 \%$ (37). Direct comparison of these results with ours is limited by differences in the study populations and method of characterizing Mycoplasma spp. While we used sequence analysis of V3-V4 hypervariable region of the $16 \mathrm{~S}$ rRNA gene, which samples only a fraction of the amplicons, and is less sensitive compared to PCR, the other studies used PCR, ELISA, or molecular hybridization to identify and characterize Mycoplasma spp. Some of the primers used in these methods do not react with all Mycoplasma spp. strains (38).

In the present study, we did not observe significant associations between prevalent Mycoplasma spp. and prevalent hrHPV infection. The results of previous studies on the association between prevalent $M$. genitalium, $M$. hominis, and hrHPV infections have been contradictory $(6,8,9)$. Consistent with our findings, no significant associations were observed between prevalent
M. genitalium or M. hominis and prevalent hrHPV infection in studies conducted among Brazilian (8) and South Korean (9) women. Contrary to our results, Biernat-Sudolska et al. reported positive associations between prevalent $M$. genitalium or M. hominis and prevalent hrHPV infection among women (6). The inconsistence of these studies may be due to inherent differences in the populations studied and the methodologies used. In the present study, we also observed significant associations between persistent $M$. hominis and persistent hrHPV infections. As similar studies on the association between persistence of Mycoplasma spp. and persistent hrHPV infection have not yet been conducted elsewhere to the best our knowledge, we were unable to compare these findings.

The mechanism by which Mycoplasma spp. may facilitate hrHPV infection or cervical carcinogenesis remains unclear. Like other sexually transmitted genital pathogens, Mycoplasma spp. may be associated with changes in epithelial cells that facilitate entry of HPV virions or with changes in the immunological response pathways that decrease the host's ability to resolve HPV infection $(39,40)$. Several bacteria, particularly those capable of establishing persistent infections, can alter host cell cycles, affect apoptotic pathways, and stimulate the production of inflammatory substances linked to DNA damage, thus potentially promote abnormal cell growth (12). 
TABLE 6 | Association between sociodemographic characteristics and potential risk factors for Mycoplasma hominis.

\begin{tabular}{|c|c|c|c|c|c|c|c|}
\hline \multirow[t]{2}{*}{ Variable } & \multirow[b]{2}{*}{ Total $n(n=194)$} & \multicolumn{3}{|c|}{ Prevalent $M$. hominis } & \multicolumn{3}{|c|}{ Persistent $M$. hominis } \\
\hline & & $n(\%)$ & OR $(95 \% \mathrm{Cl})$ & $p$-Value & & OR $(95 \% \mathrm{Cl})$ & $p$-Value \\
\hline \multicolumn{8}{|l|}{ Age, years } \\
\hline$<30$ & 19 & $7(37)$ & $0.74(0.19-2.67)$ & 0.82 & $7(37)$ & $2.98(0.39-37.7)$ & 0.41 \\
\hline 30 to $<45$ & 141 & $65(46)$ & $1.08(0.47-2.49)$ & 0.98 & $43(30)$ & $1.80(0.52-6.16)$ & 0.41 \\
\hline$\geq 45$ & 34 & $15(44)$ & Ref. (1.00) & & $9(26)$ & Ref. (1.00) & \\
\hline \multicolumn{8}{|l|}{ Body mass index, $\mathrm{kg} / \mathrm{m}^{2}$} \\
\hline Normal weight, 18.5 to $<25$ & 62 & $30(48)$ & $1.01(0.44-2.31)$ & 1.00 & $18(29)$ & $4.17(1.01-19.9)$ & 0.04 \\
\hline Overweight, 25 to $<30$ & 75 & $32(43)$ & $0.81(0.36-1.78)$ & 0.69 & $29(39)$ & $3.40(1.01-12.1)$ & 0.04 \\
\hline Obese, $\geq 30$ & 48 & $23(48)$ & Ref. (1.00) & & $10(21)$ & Ref. (1.00) & \\
\hline \multicolumn{8}{|l|}{ Marital status } \\
\hline Married & 111 & 47 (42) & $0.79(0.42-1.45)$ & 0.50 & $35(31)$ & $0.80(0.29-2.14)$ & 0.80 \\
\hline Not married & 83 & $40(48)$ & Ref. (1.00) & & $24(29)$ & Ref. (1.00) & \\
\hline \multicolumn{8}{|l|}{ Education, years completed } \\
\hline$\leq 6$ years & 23 & $8(35)$ & $0.41(0.12-1.29)$ & 0.14 & $8(35)$ & $2.57(0.47-15.7)$ & 0.36 \\
\hline $7-12$ & 125 & $53(42)$ & $0.56(0.26-1.18)$ & 0.14 & $45(36)$ & $4.58(1.27-18.0)$ & 0.01 \\
\hline$>12$ & 46 & $26(56)$ & Ref. (1.00) & & $6(13)$ & Ref. (1.00) & \\
\hline \multicolumn{8}{|c|}{ Age at sexual initiation, years } \\
\hline$\leq 19$ & 98 & $42(43)$ & $0.47(0.17-1.23)$ & 0.13 & $35(36)$ & $3.25(0.48-25.1)$ & 0.28 \\
\hline 19-22 & 67 & $29(43)$ & $0.48(0.16-1.32)$ & 0.17 & $20(30)$ & $2.17(0.30-17.5)$ & 0.58 \\
\hline$>22$ & 26 & $16(61)$ & Ref. (1.00) & & $3(11)$ & Ref. (1.00) & \\
\hline \multicolumn{8}{|l|}{ Total lifetime sex partners } \\
\hline 1 & 31 & $17(55)$ & $0.91(0.34-2.42)$ & 1.00 & $5(16)$ & $0.30(0.05-1.55)$ & 0.18 \\
\hline $2-4$ & 106 & $38(36)$ & $0.42(0.20-0.85)$ & 0.01 & $37(35)$ & $0.95(0.27-3.03)$ & 1.00 \\
\hline$\geq 5$ & 56 & $32(57)$ & Ref. (1.00) & & $17(30)$ & Ref. (1.00) & \\
\hline \multicolumn{8}{|l|}{ Vaginal pH } \\
\hline$<4.5$ & 9 & $1(11)$ & $0.13(0.01-1.12)$ & 0.06 & $2(22)$ & $0.14(0.01-0.90)$ & 0.03 \\
\hline 4.5 to $<5.5$ & 13 & $4(31)$ & $0.48(0.14-1.64)$ & 0.24 & $4(31)$ & $0.86(0.11-10.2)$ & 1.00 \\
\hline$\geq 5.5$ & 172 & $82(48)$ & Ref. (1.00) & & $53(31)$ & Ref. (1.00) & \\
\hline \multicolumn{8}{|l|}{ HIV status } \\
\hline Yes & 139 & $48(34)$ & $0.21(0.10-0.44)$ & $<0.001$ & $58(42)$ & 51.6 (6.99->999) & $<0.001$ \\
\hline No & 55 & $39(71)$ & Ref. (1.00) & & $1(2)$ & Ref. (1.00) & \\
\hline
\end{tabular}

Table shows exact odds ratios (ORs) and 95\% confidence intervals (C/s) based on logistic regression models; $n=$ number of women.

TABLE 7 | Multivariate association between M. genitalium and M. hominis, and high-risk human papillomavirus (hrHPV) infections.

\begin{tabular}{|c|c|c|c|c|c|}
\hline & \multirow[t]{2}{*}{$N$ positive/negative } & Exact odds ratio $(95 \% \mathrm{Cl})$ & $p$-Value & Exact odds ratio $(95 \% \mathrm{Cl})$ & $p$-Value \\
\hline & & \multicolumn{4}{|c|}{ Prevalent hrHPV } \\
\hline Prevalent M. genitalium & $15 / 45$ & & & & \\
\hline Positive & & $0.65(0.28-1.44)$ & 0.33 & $0.68(0.29-1.53)$ & 0.41 \\
\hline Negative & & Ref. (1.00) & & Ref. (1.00) & \\
\hline \multirow[t]{2}{*}{ Negative } & & Ref. (1.00) & & Ref. (1.00) & \\
\hline & & \multicolumn{4}{|c|}{ Persistent hrHPV } \\
\hline Persistent M. genitalium & $7 / 44$ & & & & \\
\hline Positive & & $0.80(0.22-2.64)$ & 0.90 & $0.43(0.10-1.87)$ & 0.32 \\
\hline Negative & & Ref. (1.00) & & Ref. (1.00) & \\
\hline
\end{tabular}

Table shows odds ratios (ORs) and 95\% confidence intervals (Cls) for women with prevalent or persistent $\mathrm{M}$. genitalium and $\mathrm{M}$. hominis, compared to women who were negative. The ORs and $95 \% \mathrm{Cl}$ were based on exact logistic regression models.

$n=$ number of women with hrHPV infection, who were positive or negative for M. genitalium and M. hominis.

Model 1 = age-adjusted.

Model $2=$ model $1+$ HIV status (positive vs. negative). 
Cervical somatic cells' methylation is another potential pathway through which Mycoplasma spp. can be associated with cervical carcinogenesis (41-47). Several Mycoplasma species infect eukaryotic cells, where they activate genes and have been associated with malignant transformations $(14,17,48,49)$. Recently, it was shown that upon cellular infection, CG- and GATC-specific DNA cytosine methyltransferases from some Mycoplasma spp. efficiently translocate to the nucleus and methylate several regions of the genome (50). This dramatic and chaotic modification of the somatic epigenetic cellular landscape likely results in a disorganized pattern of gene expression. Zhang et al. demonstrated that infections of HPV E6- and E7-immortalized cervical cells by some Mycoplasma spp., including M. genitalium and M. hominis, were associated with profound alterations in cytokines' gene expression (19). They concluded that chronic and persistent infection with these seemingly low-virulence mycoplasmas could gradually but significantly affect many important biological characteristics of mammalian cells and lead to malignant transformation $(14,15,51)$.

Little is known about the factors associated with presence of Mycoplasma spp. in the female genitalia. HIV positive women in our study were more likely to be positive for both $M$. genitalium and M. hominis. However, other indicators of risky sexual behavior, including earlier age at sexual initiation and number of lifetime sexual partners, were not associated between M. genitalium and M. hominis, and either vaginal M. genitalium or M. hominis in this study. We did not observe significant associations between M. genitalium and M. hominis, and sociodemographic variables including participants' age, marital status, and level of education. These results are consistent with a previous study conducted among Kenyan women (35). The Kenyan study of female sex workers also reported that using condoms most or all the time was more likely to be associated with presence of M. genitalium (35), while sexual intercourse during menstruation was inversely associated with M. genitalium. Given that the level of condom use in our study population was very low, we were unable to examine its relation to $M$. genitalium and M. hominis positivity.

Our study has several important limitations. We identified M. genitalium and M. hominis in the vaginal microbiota by

\section{REFERENCES}

1. Stewart BW, Wild CP. World Cancer Report 2014. Lyon: International Agency for Research on Cancer (2014). 632 p.

2. Bodily J, Laimins LA. Persistence of human papillomavirus infection: keys to malignant progression. Trends Microbiol (2011) 19(1):33-9. doi:10.1016/j. tim.2010.10.002

3. Schiffman M, Castle PE, Jeronimo J, Rodriguez AC, Wacholder S. Human papillomavirus and cervical cancer. Lancet (2007) 370(9590):890-907. doi:10.1016/S0140-6736(07)61416-0

4. Tota JE, Chevarie-Davis M, Richardson LA, Devries M, Franco EL. Epidemiology and burden of HPV infection and related diseases: implications for prevention strategies. Prev Med (2011) 53(Suppl 1):S12-21. doi:10.1016/j.ypmed.2011.08.017

5. Famooto A, Almujtaba M, Dareng E, Akarolo-Anthony S, Ogbonna C, Offiong R, et al. RPS19 and TYMS SNPs and prevalent high risk human papilloma virus infection in Nigerian women. PLoS One (2013) 8(6):e66930. doi:10.1371/journal.pone.0066930 sequencing the V3-V4 hypervariable regions of the 16S rRNA gene, this method has not been clinically validated as a test for Mycoplasma spp. As sequencing the $16 \mathrm{~S}$ rRNA gene is a sampling approach, the power to detect M. genitalium or M. hominis is correlated with the depth of sequencing and limited to $x$ logs if $10^{x}$ reads are sequenced per sample. Also, our sample size was small, as indicated by the wide confidence intervals. Therefore, we advise that our results be interpreted with caution and recommend additional studies with larger sample sizes should be conducted. Because we evaluated M. genitalium and M. hominis, and hrHPV infections at the same time, we are unable to rule out reverse causation.

In conclusion, our study shows significant associations between persistent $M$. hominis in the vaginal microbiota and persistent hrHPV infections. These findings suggest that M. hominis and possibly, other mycoplasmas may play a role in hrHPV induced cervical carcinogenesis and warrant further studies. If confirmed, testing and treating for M. hominis and possibly, other mycoplasma in women with hrHPV infections may preempt hrHPV persistence and help alleviate the burden of cervical cancer.

\section{AUTHOR CONTRIBUTIONS}

SA conducted the data analyses, interpreted the data, and drafted the manuscript. CA designed and obtained funding for the study. AF processed the samples, performed biochemical assays, and collated the laboratory data. BM, DZ, JR, and CA contributed to the data analysis and interpretation. Each author approved the final version of the manuscript and agreed to be accountable for all aspects of the work.

\section{FUNDING}

This work was supported by the UM-Capacity Development for Research in AIDS Associated Malignancy Grant (NIH/ NCI 1D43CA153792-01) and African Collaborative Center for Microbiome and Genomics Research Grant (NIH/NHGRI 1U54HG006947).
6. Biernat-Sudolska M, Szostek S, Rojek-Zakrzewska D, Klimek M, KoszVnenchak M. Concomitant infections with human papillomavirus and various Mycoplasma and Ureaplasma species in women with abnormal cervical cytology. Adv Med Sci (2011) 56(2):299-303. doi:10.2478/v10039-011-0028-9

7. da Silva Barros NK, Costa MC, Alves RR, Villa LL, Derchain SF, Zeferino LC, et al. Association of HPV infection and Chlamydia trachomatis seropositivity in cases of cervical neoplasia in Midwest Brazil. J Med Virol (2012) 84(7):1143-50. doi:10.1002/jmv.23312

8. de Abreu AL, Malaguti N, Souza RP, Uchimura NS, Ferreira ÉC, Pereira MW, et al. Association of human papillomavirus, Neisseria gonorrhoeae and Chlamydia trachomatis co-infections on the risk of high-grade squamous intraepithelial cervical lesion. Am J Cancer Res (2016) 6(6):1371-83.

9. Kim HS, Kim TJ, Lee IH, Hong SR. Associations between sexually transmitted infections, high-risk human papillomavirus infection, and abnormal cervical Pap smear results in OB/GYN outpatients. J Gynecol Oncol (2016) 27(5):e49. doi:10.3802/jgo.2016.27.e49

10. Magana-Contreras M, Contreras-Paredes A, Chavez-Blanco A, Lizano M, De la Cruz-Hernandez Y, De la Cruz-Hernandez E. Prevalence of sexually 
transmitted pathogens associated with HPV infection in cervical samples in a Mexican population. J Med Virol (2015) 87(12):2098-105. doi:10.1002/ jmv. 24278

11. Sun XW, Kuhn L, Ellerbrock TV, Chiasson MA, Bush TJ, Wright TC Jr. Human papillomavirus infection in women infected with the human immunodeficiency virus. N Engl J Med (1997) 337(19):1343-9. doi:10.1056/ NEJM199711063371903

12. Thomas RM, Jobin C. The microbiome and cancer: is the 'oncobiome' mirage real? Trends Cancer (2015) 1(1):24-35. doi:10.1016/j.trecan.2015.07.005

13. Huang S, Li JY, Wu J, Meng L, Shou CC. Mycoplasma infections and different human carcinomas. World J Gastroenterol (2001) 7(2):266-9. doi:10.3748/wjg. v7.i2.266

14. Zhang S, Tsai S, Lo SC. Alteration of gene expression profiles during Mycoplasma-induced malignant cell transformation. BMC Cancer (2006) 6:116. doi:10.1186/1471-2407-6-116

15. Feng SH, Tsai S, Rodriguez J, Lo SC. Mycoplasmal infections prevent apoptosis and induce malignant transformation of interleukin-3-dependent 32D hematopoietic cells. Mol Cell Biol (1999) 19(12):7995-8002. doi:10.1128/ MCB.19.12.7995

16. Rottem S. Interaction of mycoplasmas with host cells. Physiol Rev (2003) 83(2):417-32. doi:10.1152/physrev.00030.2002

17. Namiki K, Goodison S, Porvasnik S, Allan RW, Iczkowski KA, Urbanek C, et al. Persistent exposure to Mycoplasma induces malignant transformation of human prostate cells. PLoS One (2009) 4(9):e6872. doi:10.1371/journal. pone. 0006872

18. Sasaki H, Igaki H, Ishizuka T, Kogoma Y, Sugimura T, Terada M. Presence of Streptococcus DNA sequence in surgical specimens of gastric cancer. Jpn J Cancer Res (1995) 86(9):791-4. doi:10.1111/j.1349-7006.1995.tb03086.x

19. Zhang S, Wear DJ, Lo S. Mycoplasmal infections alter gene expression in cultured human prostatic and cervical epithelial cells. FEMS Immunol Med Microbiol (2000) 27(1):43-50. doi:10.1111/j.1574-695X.2000.tb01410.x

20. van Hamont D, van Ham MA, Bakkers JM, Massuger LF, Melchers WJ. Evaluation of the SPF10-INNO LiPA human papillomavirus (HPV) genotyping test and the roche linear array HPV genotyping test. J Clin Microbiol (2006) 44(9):3122-9. doi:10.1128/JCM.00517-06

21. Kleter B, van Doorn LJ, Schrauwen L, Molijn A, Sastrowijoto S, ter Schegget J, et al. Development and clinical evaluation of a highly sensitive PCR-reverse hybridization line probe assay for detection and identification of anogenital human papillomavirus. J Clin Microbiol (1999) 37(8): 2508-17.

22. Melchers WJ, Bakkers JM, Wang J, de Wilde PC, Boonstra H, Quint WG, et al. Short fragment polymerase chain reaction reverse hybridization line probe assay to detect and genotype a broad spectrum of human papillomavirus types. Clinical evaluation and follow-up. Am J Pathol (1999) 155(5):1473-8. doi:10.1016/S0002-9440(10)65462-4

23. Dareng EO, Ma B, Famooto AO, Akarolo-Anthony SN, Offiong RA, Olaniyan $\mathrm{O}$, et al. Prevalent high-risk HPV infection and vaginal microbiota in Nigerian women. Epidemiol Infect (2016) 144(1):123-37. doi:10.1017/ S0950268815000965

24. Caporaso JG, Lauber CL, Walters WA, Berg-Lyons D, Huntley J, Fierer N, et al. Ultra-high-throughput microbial community analysis on the Illumina HiSeq and MiSeq platforms. ISME J (2012) 6(8):1621-4. doi:10.1038/ismej. 2012.8

25. Caporaso JG, Kuczynski J, Stombaugh J, Bittinger K, Bushman FD, Costello EK, et al. QIIME allows analysis of high-throughput community sequencing data. Nat Methods (2010) 7(5):335-6. doi:10.1038/nmeth.f.303

26. Magoc T, Salzberg SL. FLASH: fast length adjustment of short reads to improve genome assemblies. Bioinformatics (2011) 27(21):2957-63. doi:10.1093/ bioinformatics/btr507

27. Edgar RC, Haas BJ, Clemente JC, Quince C, Knight R. UCHIME improves sensitivity and speed of chimera detection. Bioinformatics (2011) 27(16):2194200. doi:10.1093/bioinformatics/btr381

28. McDonald D, Price MN, Goodrich J, Nawrocki EP, DeSantis TZ, Probst A, et al. An improved Greengenes taxonomy with explicit ranks for ecological and evolutionary analyses of bacteria and archaea. ISME J (2012) 6(3):610-8. doi:10.1038/ismej.2011.139

29. Oksanen J, Blanchet FG, Friendly M, Kindt R, Legendre P, McGlinn D, et al. vegan: Community Ecology Package. R package version (2011). Available from: https://cran.r-project.org/web/packages/vegan/index.html
30. Franklin JD, Guidry A, Brinkley JF. A partnership approach for Electronic Data Capture in small-scale clinical trials. J Biomed Inform (2011) 44(Suppl 1): S103-8. doi:10.1016/j.jbi.2011.05.008

31. Harris PA, Taylor R, Thielke R, Payne J, Gonzalez N, Conde JG. Research electronic data capture (REDCap) - a metadata-driven methodology and workflow process for providing translational research informatics support. J Biomed Inform (2009) 42(2):377-81. doi:10.1016/j.jbi.2008.08.010

32. Cox DR, Snell EJ. Analysis of Binary Data. 2nd ed. Boca Raton: Chapman and Hall (1989).

33. Hirji KF. Exact Analysis of Discrete Data. Boca Raton: Chapman and Hall (2006).

34. Ravel J, Gajer P, Abdo Z, Schneider GM, Koenig SS, McCulle SL, et al. Vaginal microbiome of reproductive-age women. Proc Natl Acad Sci U S A (2011) 108(Suppl 1):4680-7. doi:10.1073/pnas.1002611107

35. Gomih-Alakija A, Ting J, Mugo N, Kwatampora J, Getman D, Chitwa M, et al. Clinical characteristics associated with Mycoplasma genitalium among female sex workers in Nairobi, Kenya. J Clin Microbiol (2014) 52(10):3660-6. doi:10.1128/JCM.00850-14

36. Mamadou S, Laouel Kader A, Rabiou S, Aboubacar A, Soumana O, Garba A, et al. Prevalence of the HIV infection and five other sexually-transmitted infections among sex workers in Niamey, Niger. Bull Soc Pathol Exot (2006) 99(1):19-22. doi:10.3185/pathexo2623

37. Djigma F, Ouedraogo C, Sagna T, Ouermi D, Sanogo K, Bisseye C, et al. HIV-infected women of Burkina Faso: a "reservoir" of Mycoplasma infection. J Infect Dev Ctries (2011) 5(3):176-81.

38. Waites KB, Xiao L, Paralanov V, Viscardi RM, Glass JI. Molecular methods for the detection of Mycoplasma and Ureaplasma infections in humans: a paper from the 2011 William Beaumont Hospital Symposium on molecular pathology. J Mol Diagn (2012) 14(5):437-50. doi:10.1016/j.jmoldx.2012. 06.001

39. Paba P, Bonifacio D, Di Bonito L, Ombres D, Favalli C, Syrjänen K, et al. Co-expression of HSV2 and Chlamydia trachomatis in HPV-positive cervical cancer and cervical intraepithelial neoplasia lesions is associated with aberrations in key intracellular pathways. Intervirology (2008) 51(4):230-4. doi:10.1159/000156481

40. Verteramo R, Pierangeli A, Mancini E, Calzolari E, Bucci M, Osborn J, et al. Human Papillomaviruses and genital co-infections in gynaecological outpatients. BMC Infect Dis (2009) 9:16. doi:10.1186/1471-2334-9-16

41. Brentnall AR, Vasiljevic N, Scibior-Bentkowska D, Cadman L, Austin J, Cuzick J, et al. HPV33 DNA methylation measurement improves cervical pre-cancer risk estimation of an HPV16, HPV18, HPV31 and Itextit\{EPB41L3\} methylation classifier. Cancer Biomark (2015) 15(5):669-75. doi:10.3233/ CBM-150507

42. Brentnall AR, Vasiljević N, Scibior-Bentkowska D, Cadman L, Austin J, Szarewski A, et al. A DNA methylation classifier of cervical precancer based on human papillomavirus and human genes. Int J Cancer (2014) 135(6):1425-32. doi:10.1002/ijc. 28790

43. Vasiljevic N, Scibior-Bentkowska D, Brentnall A, Cuzick J, Lorincz A. A comparison of methylation levels in HPV18, HPV31 and HPV33 genomes reveals similar associations with cervical precancers. J Clin Virol (2014) 59(3):161-6. doi:10.1016/j.jcv.2013.12.014

44. Castle PE, Schiffman M, Scott DR, Sherman ME, Glass AG, Rush BB, et al Semiquantitative human papillomavirus type 16 viral load and the prospective risk of cervical precancer and cancer. Cancer Epidemiol Biomarkers Prev (2005) 14(5):1311-4. doi:10.1158/1055-9965.EPI-04-0799

45. Clarke MA, Wentzensen N, Mirabello L, Ghosh A, Wacholder S, Harari A, et al. Human papillomavirus DNA methylation as a potential biomarker for cervical cancer. Cancer Epidemiol Biomarkers Prev (2012) 21(12):2125-37. doi:10.1158/1055-9965.EPI-12-0905

46. Lorincz AT. Cancer diagnostic classifiers based on quantitative DNA methylation. Expert Rev Mol Diagn (2014) 14(3):293-305. doi:10.1586/14737159. 2014.897610

47. Louvanto K, Franco EL, Ramanakumar AV, Vasiljević N, ScibiorBentkowska D, Koushik A, et al. Methylation of viral and host genes and severity of cervical lesions associated with human papillomavirus type 16. Int J Cancer (2015) 136(6):E638-45. doi:10.1002/ijc.29196

48. Yavlovich A, Katzenell A, Tarshis M, Higazi AA, Rottem S. Mycoplasma fermentans binds to and invades HeLa cells: involvement of plasminogen and urokinase. Infect Immun (2004) 72(9):5004-11. doi:10.1128/IAI.72.9.5004-5011.2004 
49. Baseman JB, Reddy SP, Dallo SF. Interplay between Mycoplasma surface proteins, airway cells, and the protean manifestations of Mycoplasma-mediated human infections. Am J Respir Crit Care Med (1996) 154(4 Pt 2):S137-44. doi:10.1164/ajrccm/154.4_Pt_2.S137

50. Chernov AV, Reyes L, Xu Z, Gonzalez B, Golovko G, Peterson S, et al. Mycoplasma CG- and GATC-specific DNA methyltransferases selectively and efficiently methylate the host genome and alter the epigenetic landscape in human cells. Epigenetics (2015) 10(4):303-18. doi:10.1080/15592294.2015.1020000

51. Tsai S, Wear DJ, Shih JW, Lo SC. Mycoplasmas and oncogenesis: persistent infection and multistage malignant transformation. Proc Natl Acad Sci U S A (1995) 92(22):10197-201. doi:10.1073/pnas.92.22.10197
Conflict of Interest Statement: The authors declare that the research was conducted in the absence of any commercial or financial relationships that could be construed as a potential conflict of interest.

Copyright (C) 2017 Adebamowo, Ma, Zella, Famooto, Ravel, Adebamowo and ACCME Research Group. This is an open-access article distributed under the terms of the Creative Commons Attribution License (CC BY). The use, distribution or reproduction in other forums is permitted, provided the original author(s) or licensor are credited and that the original publication in this journal is cited, in accordance with accepted academic practice. No use, distribution or reproduction is permitted which does not comply with these terms. 